\title{
Proposed Suitable Methods to Detect Transient Regime Switching to Improve Power Quality with Wavelet Transform
}

\section{Javad Safaee Kuchaksaraee*, Soodabeh Soleymani, Babak Mozafari}

Department of Electrical Engineering, Science and Research Branch, Islamic Azad University, Tehran, Iran

Study Area: Tehran, Iran

Coordinates: $35.6892^{\circ} \mathrm{N}, 51.3890^{\circ} \mathrm{E}$

Key words: Transient states, Capacitor bank Switching of capacitors, Internal fault current.

\section{Abstract}

The increasing consumption of electrical energy and the use of non-linear loads that create transient regime states in distribution networks is increasing day by day. This is the only reason due to which the analysis of power quality for energy sustainability in power networks has become more important. Transients are often created by energy injection through switching or lightning and make changes in voltage and nominal current. Sudden increase or decrease in voltage or current makes characteristics of the transient regime. This paper shed some lights on the capacitor bank switching, which is one of the main causes for oscillatory transient regime states in the distribution network, using wavelet transform. The identification of the switching current of capacitor bank and the internal fault current of the transformer to prevent the unnecessary outage of the differential relay, it propose a new smart method. The accurate performance of this method is shown by simulation in EMTP and MATLAB (matrix laboratory) software.

how to insulate them and/or design other relevant insulation equipment. The parallel capacitor bank switching is one of the most important factors that cause transient states in distribution networks. If this capacitor bank switching occurs at the voltage moment of 90 degrees, it leads to excess current of the second transformer which can lead to failure to detect this current by the differential relay. Further, the differential relay identif ies this current as an internal fault and commands to cut the breakers at both ends of the transformer and causes the unwanted outage in the distribution system. This affects the power quality and reliability of the network. Thus it is necessary to separate and detect the time and location of this type of transients in order to avoid such unnecessary outage of the differential relay and contribute to the network stability and reliability (Soodabeh \& Soleymani, 2014).

The transient states of a power system are the nonperiodic signals. It is notable that the Fourier transform is defined for the periodic signals. Therefore, the Fourier transform is not a suitable method for analyzing the transient states of a power system. In other words, the Fourier transform is usually used for the steady states of a power system.

*Corresponding Author:j_safaee@yahoo.com 
A method is also in use which is based on calculating the disturbance energy caused by capacitor bank switching in a time period (Parsons et al., 200o). The disadvantage of this method is the use of three-phase voltage and current to calculate disturbance energy. Using the Kalman filter, the location and the excess increase of the voltage of capacitor bank switching could be identified (Kim et al., 2002). A method based on the identification and classification of power disturbances using fuzzy logic and the genetic algorithm has also been forwarded (Boris \& Peter, 2006; Wang \& Tseng, 2011). Its disadvantage is to require a long duration of calculation. A method was also proposed by Abu-Elanien \& Salama (2009) based on the classification of power disturbances using the neural network. However, it requires training data and the network training is time-consuming due to which it disqualify. Recently, wavelet transform has also been used to detect the time, location and disturbance classification of power quality. Mohammadi et al., 2013a forwarded a method that combines wavelet transform and neural network. A combination of wavelet transform and fuzzy logic is used for the identification and classification of the power quality of disturbances (Karthik et al., 2011). Their benef it is to use of wavelet transform to reduce data and computing time compared to the previous methods.

In the present study, we investigate and determined the switching capacitor bank which is one of the causes of making the states of isolation transient in distribution networks by using wavelet transform identify switching capacitor banks and internal fault current of the transformer. We have tried to present a new and intelligent algorithm to prevent cutting the differential relay.We simulated this algorithm in IEEE standard 14 base system and found results by using MATLAB and EMTP softwares.

\section{Wavelet Transform (a):}

A multi-scale feature makes wavelet and signals able to transform and analyze the number of features. We could use such features to separate the internal fault of Trans from capacitor switching bank (Karthik et al., 2011). The process of multi-resolution analyzing of a signal is illustrated in fig.: 1. Each stage includes two digital filters and two sampling rate reducer. The first filter $\mathrm{g}$ [.] is a main discrete wavelet which is originally overpass and the second one $h[$.$] is the symmetry of the first one with low$ past. The outputs of these filters create the component D1

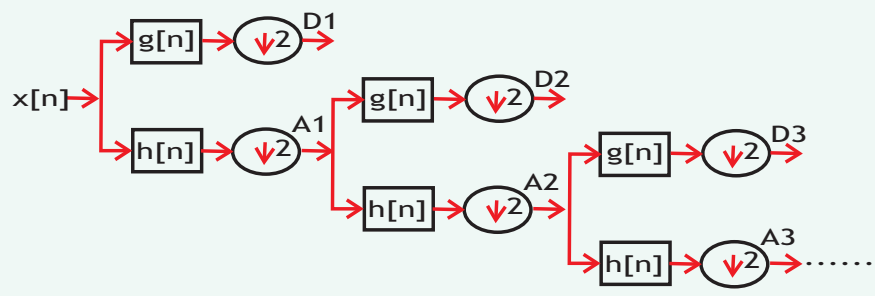

Figure: 1. Analyzing the band of discrete wavelet transformation, $\mathrm{g}[\mathrm{n}]$ is overpass filterand $\mathrm{h}[\mathrm{n}]$ is a low pass filter. and estimation $A_{1}$, respectively. Estimated A1 analyzes again and proceed as fig.: 1. All wavelet transformations can be distracted by low pass filter h which complies the condition of the standard symmetric filter.

$$
H(\mathrm{z}) H\left(\mathrm{z}^{-1}\right)+H(-\mathrm{z}) H\left(-\mathrm{z}^{-1}\right)=1
$$

$\mathrm{H}(\mathrm{z})$ is the $\mathrm{z}$-transformation of filter $h$. The complement of its overpass filter is def ined as follows:

(2) $\quad G(z)=z H\left(-z^{-1}\right)=1$

By increasing the length (I Indice) a sequence of filters is concluded as follows:

(3) $\quad G_{1+1}(z)=G\left(z^{2}\right)=H_{i}(z), i=0, \ldots \ldots . ., 1-1$

Using the basic condition it can be converted to following double-scale relation:

（4） $\quad \mathrm{h}_{\mathrm{i}+1}(k)=[h] \uparrow 2^{\mathrm{i}}{ }^{*} \mathrm{~h}_{1}(\mathrm{k}) ; \quad \mathrm{G}_{\mathrm{i}+1}(k)=[g] \uparrow 2^{\mathrm{i}}{ }^{*} \mathrm{~h}_{1}(\mathrm{k})$

Indice $\mathrm{m}$ shows the sampling rate increasing with factor $m$ and $k$ has been sampled equally in a discrete time. The wavelet is normalized and scale functions $\varphi \mathrm{i}, 1(\mathrm{k})$ and $\psi \mathrm{i}, 1(\mathrm{k})$ are def ined as follows:

\section{(5) $\quad \varphi \mathrm{i}, 1(\mathrm{k})=2^{\mathrm{i} / 2} \mathrm{hl}_{1}\left(\mathrm{k}-2^{\mathrm{i}} \mathrm{l}\right) ; \quad \quad \psi \mathrm{i}, 1(\mathrm{k})=2^{\mathrm{i} / 2} \mathrm{gl}_{1}\left(\mathrm{k}-2^{\mathrm{i}} \mathrm{l}\right)$}

The factor is the inner product of normalization. $i$ and 1 are scale parameter and reverse parameter, respectively. Analyzing of discrete wavelet transformation is shown in relation (6):

(6)

$$
\mathrm{a}_{(\mathrm{i})}(\mathrm{l})=\mathrm{x}(\mathrm{k})^{*} \varphi \mathrm{i}, 1(\mathrm{k}) ; \quad \mathrm{d}_{(\mathrm{i})}(\mathrm{l})=\mathrm{x}(\mathrm{k})^{*} \psi \mathrm{i}, \mathrm{l}(\mathrm{k}) ;
$$

$\mathrm{a}_{(\mathrm{i})}(\mathrm{l})$ and $\mathrm{d}_{(\mathrm{i})}(\mathrm{l})$ are the estimation coeff icients and partial coefficients, respectively.

\section{Proposed Algorithm (b):}

Since the differential relay is used for protecting internal fault of Trans, it should only protect the Trans against internal fault and do not react into other faults which are temporary, such as transients caused by capacitor bank switching. Therefore, separation of these two is essential for stability and power quality. It has been reported by Mohammadi et al. (2013b) that the family of $\mathrm{db}$ is appropriate in using the analysis of electronic signals by wavelet transformation. Indeed, because of the proximity of Switching current slope and internal current of Trans, wavelet $\mathrm{db}$ is able to separate them from each other. In this article using two following principles we investigated and analyze the differential current of Trans:

1. To find the starting point of switching, we used level D1, as we can observe the fastest changes and frequencies in this level.

2. To separate the internal current from the capacitor bank switching current, we used level $\mathrm{D}_{5}$ because of the slowness of frequency changes and more clarity of signal components.

According to figures 1 \& a-3, we realized that the internal fault current with less slope and more time is increasing compared with the capacitive switching current. Hence, it is expected that the internal fault current of Trans has less frequency and domain than capacitive switching current. Inspite of it, at the moment of switching, due to more slope of capacitive switching current in comparison with an internal fault of Trans, more frequency and domain are expected (Guzman et al., 2001; Kanitpanyacharoean \& Premrudeepreechacharn, 2004).

As per the situation that is the capacitive switching current 
TECHNOSCIENCE ARTICLE

has a high slope at the moment of switching, in this article we used db1 because of the sensitivity of main wavelet to sharp changes. Fig.:b-3 illustrates the signal of an internal fault of Trans which is taken from 5 levels of decomposed wavelet alteration.

In $\mathrm{fig}$.: $\mathrm{c}-3$ five levels of the decomposed waveles alternation are taken from the signal of capacitor bank switching. The process is as follows, according to two started principles, first we analyzed the signal of differential current of trains in all three phases with db1 in level Diand A5. We used level Di to distinguish the moment of fault occurrence or switching capacitor and then investigate the first two peaks from this point. Even if in one phase the first peak named $\mathrm{X}$ is less than the second peak named $\mathrm{Y}$, the internal fault current and relay commands breakers to cut
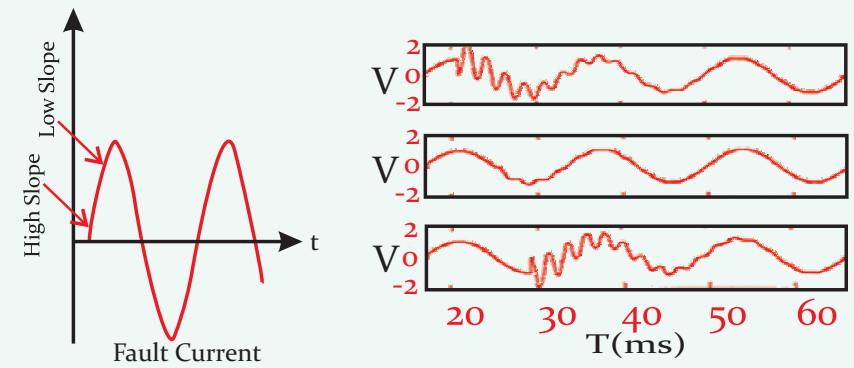

Figure:b-1.Differential current Figure:b-ii. Transient caused by of internal fault of Trans. capacitor switching bank.

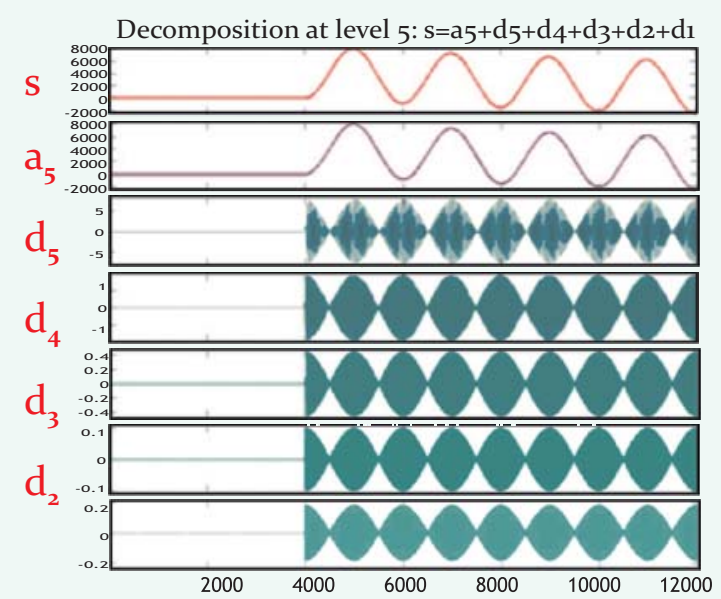

Figure: b-iii.Transformation of discrete wavelet of internal fault signal of Transat 0.04 second.

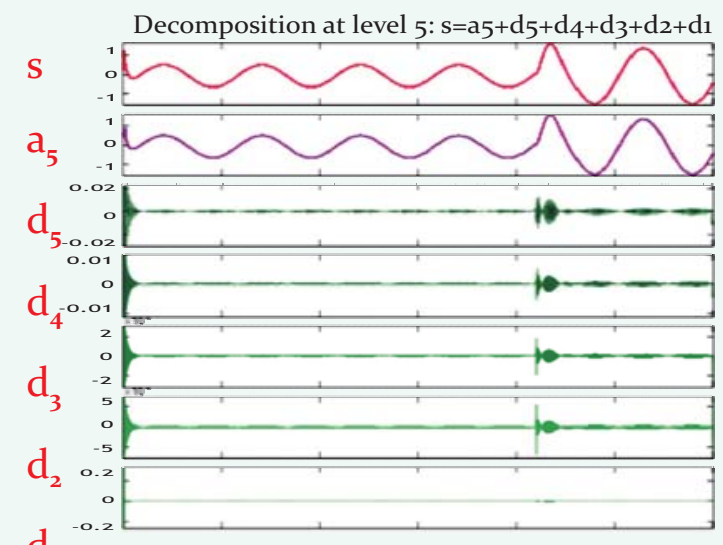

Figure.b-iv. Transformation of discrete wavelet taken from switching current signal at 0.84 second.

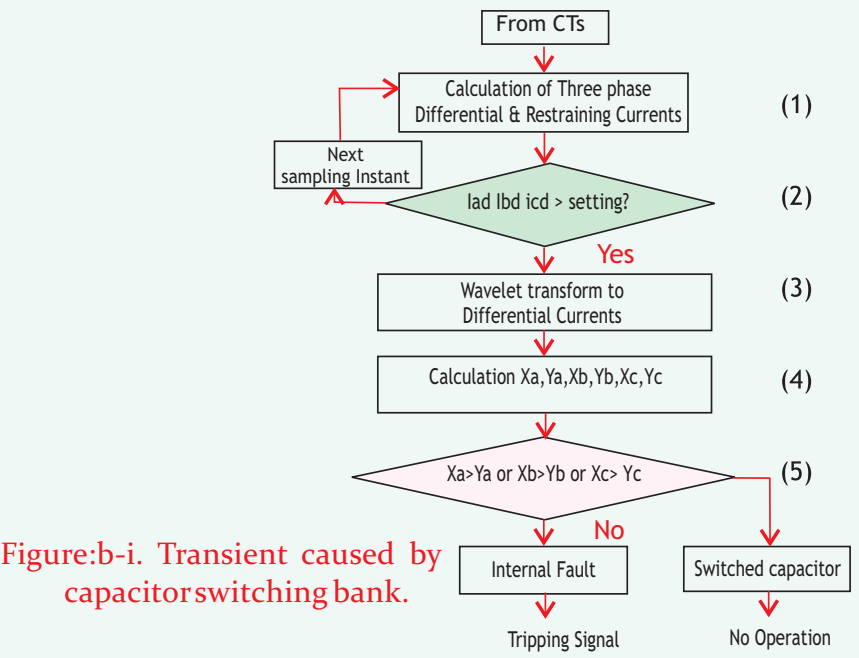

the current and if it was more than Y, relay doesn't command to cut the current. Thealgorithm of this process is shown in fig.: e-3.

\section{Simulation (c):}

In order to gaining the information required for the proposed algorithm, the power system of figure 1-4 which includes a voltage source, a distribution Trans, current trances, three loads and three capacitors for power factor correction, and is simulated in two softwares EMTP and MATLAB (matrix laboratory) is used. The values related to each element are listed in Appendix A. To achieve the validity of proposed algorithm, we studied five type of current faults in power system in part 4 and proved the validity of algorithm in all types.

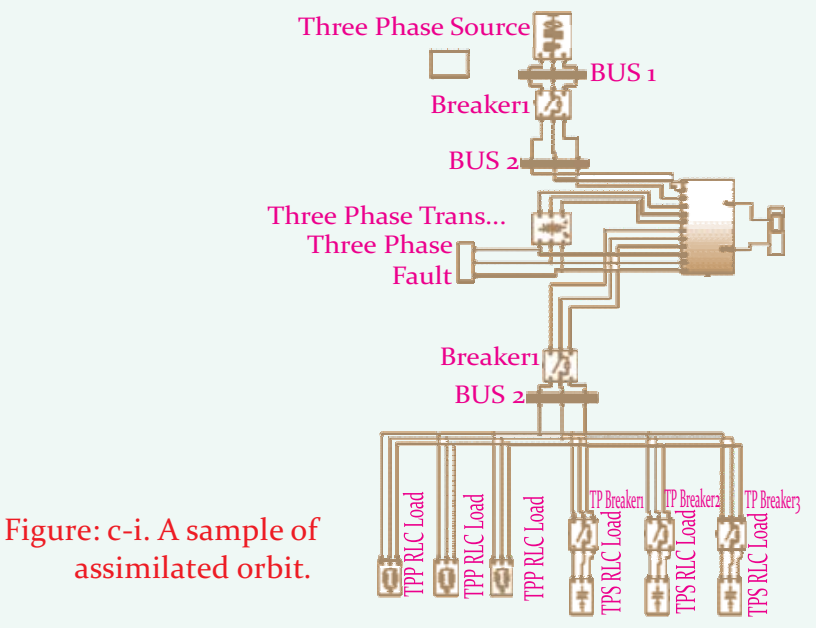

The additional current caused by capacitive switching bank (c-i): to investigate the proposed algorithm we generated an additional current caused by capacitive bank switching in stimulated orbit in 0.840 seconds, which is the peak of voltage of phase a (figure 1-1-4). At the time of 0.840 when changes are at level $\mathrm{D} 1$ we checked it again. In figure (2-1-4) by magnifying at level $\mathrm{D}_{5}$ we realized, that according to the algorithm, a current caused by capacitive bank switching and relay doesn 't command to cut the current.

Internal fault of signal phase to ground (c-ii): to investigate algorithm, the fault of one phase on the ground was tested. In this 
Decomposition at level $5: \mathrm{s}=\mathrm{a} 5+\mathrm{d}_{5}+\mathrm{d}_{4}+\mathrm{d}_{3}+\mathrm{d}_{2}+\mathrm{d}_{1}$

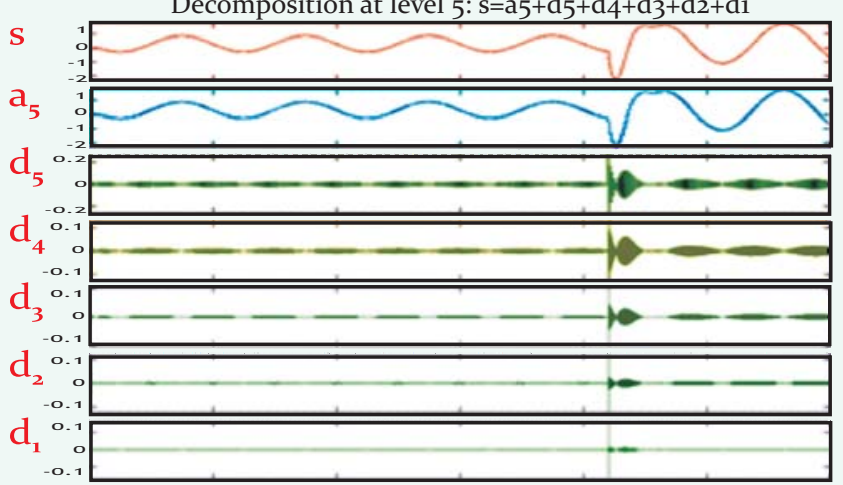

Figure:c-i-i.Additional current caused by capacitor switching bank of phasea.

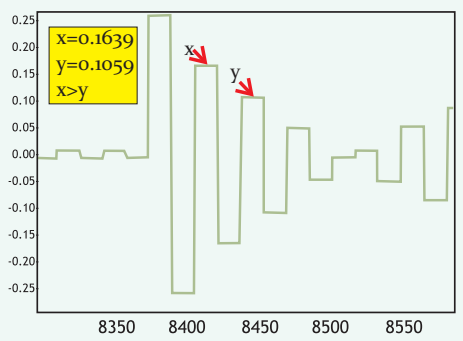

Figure:c-i-i.Additiona current caused by capacitor switching bank of phasea.

part, we studied a fault at the moment of zero voltage in phasea, as the most amount of short circuit occurred during the same moment. Fault current and wavelet transformation of singleshown in figure 1-2-4. Using level Dithe time of beginning of fault determined. As we phase fault on the ground is could see in the future, at 0.04 second, a quick change in wave shape occurs. In figure 2-2-4, magnifying in 0.04 second at $D_{5}$ we called the first two peaks by $\mathrm{X}$ and Y. According to the algorithm, it could be attained that the same. Thus such transient is known to cause by internal fault and relay commands to cut the current.

\section{Internal fault of Two-phase (c-iii)}

To investigate algorithm, internal fault of two phases on the ground was tested. In this part we studied on fault at the moment of zero voltage in phase 'a' and 'b', as the most amount of short circuit was occurred at that moment. Fault current and wavelet transformation of two-phase fault on the ground is shown in figure (1-3-4). Using a level Di the time of beginning of fault was determined. In figure (3-2-4), magnifying in 0.04 second at D5 we found the first two peaks by X and Y. According to the algorithm, it could be attained that the same. the transient is a transient caused by internal fault and relay commands to cut the current.

\section{Fault of two-phase to ground (c-iv):}

To investigate algorithm, the fault of one phase was tested on the ground. In this part, we studied on the fault at the moment of zero voltage in phase 'a'. Fault current and wavelet transformation of single-phase fault on the ground is shown in figure (c-iv-i). Using the level $\mathrm{D}_{5}$ the time of the beginning of fault is determined. As we can see in the figure, at 0.04 second, a quick change in wave shape occurs. In figure (c-iv-i) we saw the first two peaks by ' $\mathrm{X}$ ' and ' $\mathrm{Y}$ '. According to the algorithm, it could be observed that $\mathrm{X}<\mathrm{Y}$ which caused by an internal fault.

\section{Fault of Three-phase (c-v):}

To investigate algorithm the fault of one phase was tested on the ground. In this part, we studied the fault at the moment of zero voltage in phase 'a' and at the moment of 120 in phase 'b' and 'c'. Fault current and wavelet transformation of single-phase on the ground is shown in figure 4-5-1. Using level Di we could determine

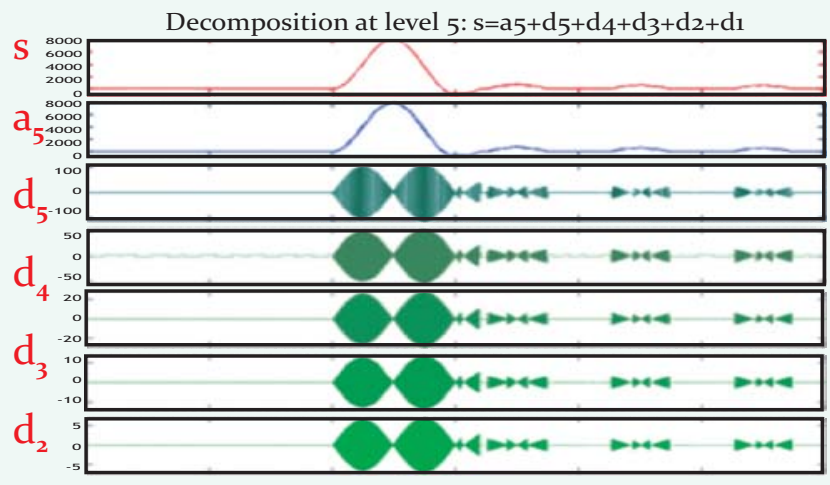

Figure:c-ii-i. Wavelet transformation of fault of phase a.
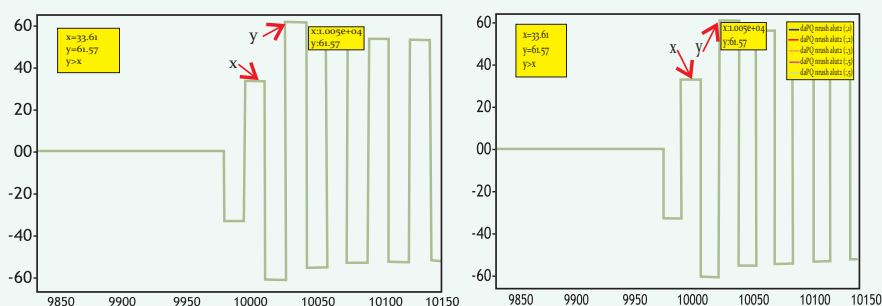

Figure:c-ii-ii. Internal fault magnification

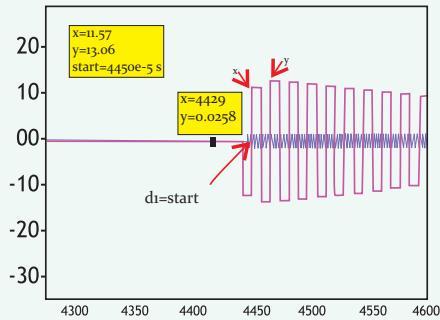

Figure:c-ii-i. Wavelet transformation of fault of two-phase.

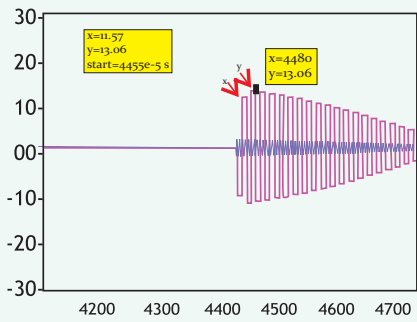

Figure:c-iv-i.Wavelet transformation of two-phase internal fault current to ground.

Figure:c-v-i.Wavelet transformation of internal faultcurrent of threephase.

the time of beginning of fault. As we can observe in the figure, at 0.04 second, a quick change in wave shape occurs. In figure (4-5-1) in part $D_{5}$ we saw the first two peaks by ' $\mathrm{X}$ ' and ' $\mathrm{Y}$ ' which can be found out that according to an algorithm. Hence, this transient is caused by internal fault and relay commands to cut the current.

Fault of Three-phase to ground (c-vi):

To investigate algorithm, fault of three phase on the ground was tested. In this part of fault at the moment of zero voltage was studied in phase a. Fault current and wavelet transformation of single-phase fault on the ground is shown in figure (c-vi-i). Using level Di the time of the beginning of fault could be determined. As we can see in figure (c-vi-i), at 0.04 second, a quick change in wave phase occurs. In figure (4-6-1) at $\mathrm{D}_{5}$ we saw the first two peaks by : Hence, this transient caused by internal fault and relay commands to cut the current.

Investigating the proposed algorithm in network IEEE 14 bas standard (c-vii): in order to ensure the validity of our proposed algorithm, the algorithm was tested and studied in standard network IEEE 14 bas standard and in all types, the fault and current of switching were checked. The results of using the algorithm in all cases of internal fault and transient caused by capacitor bank switching are listed in table 1 . 


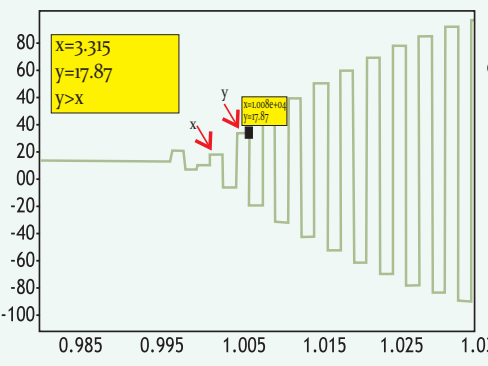

Figure:c-vi-i. Wavelet trans formation of three-phase internal faultcurrent to Figure:c-vii.Standard network ground.

IEEE 14 bas.

\begin{tabular}{|c|c|c|c|c|c|}
\hline $\begin{array}{l}\text { Type } \\
\text { inrush } \\
\text { current }\end{array}$ & phase & $\begin{array}{l}\text { Fault } \\
\text { time }\end{array}$ & Xvalue & Y value & $\begin{array}{r}\text { Test algo- } \\
\text { rithm }\end{array}$ \\
\hline Capacitor banks & A & 90 & 0.00138 & 0.000281 & $\mathrm{X}>\mathrm{Y}$ \\
\hline \multirow[t]{2}{*}{ Switching } & B & 210 & 0.00159 & $4.636 \mathrm{E}-5$ & $\mathrm{X}>\mathrm{Y}$ \\
\hline & C & -210 & 0.00138 & 0.000283 & $\mathrm{X}>\mathrm{Y}$ \\
\hline \multirow{3}{*}{$\begin{array}{l}\text { One phase-to- } \\
\text { ground fault }\end{array}$} & A & o & 0.03151 & 0.03836 & $\mathrm{X}<\mathrm{Y}$ \\
\hline & B & - & - & - & - \\
\hline & C & - & - & - & - \\
\hline \multirow[t]{3}{*}{ Two phase } & A & o & 0.01285 & 0.01441 & $\mathrm{X}<\mathrm{Y}$ \\
\hline & B & 120 & 0.01294 & 0.01448 & $\mathrm{X}<\mathrm{Y}$ \\
\hline & C & - & - & - & - \\
\hline \multirow{3}{*}{$\begin{array}{l}\text { TWO phase-to- } \\
\text { ground fault }\end{array}$} & A & o & 0.01486 & 0.01666 & $\mathrm{X}<\mathrm{Y}$ \\
\hline & B & 120 & 0.04248 & 0.04212 & $\mathrm{X}>\mathrm{Y}$ \\
\hline & $\mathrm{C}$ & -120 & - & - & - \\
\hline \multirow[t]{3}{*}{ Treephase } & A & o & 0.00732 & 0.005069 & $\mathrm{X}>\mathrm{Y}$ \\
\hline & B & 120 & 0.03311 & 0.03395 & $\mathrm{X}<\mathrm{Y}$ \\
\hline & C & -120 & 0.04043 & 0.03902 & $\mathrm{X}<\mathrm{Y}$ \\
\hline \multirow{3}{*}{$\begin{array}{l}\text { Tree phase-to- } \\
\text { ground fault }\end{array}$} & A & o & 0.01486 & 0.01665 & $\mathrm{X}<\mathrm{Y}$ \\
\hline & B & 120 & 0.04248 & 0.04215 & $\mathrm{X}>\mathrm{Y}$ \\
\hline & C & -120 & 0.04048 & 0.03906 & $\mathrm{X}>\mathrm{Y}$ \\
\hline
\end{tabular}

\section{Conclusion and recommendations:}

On this paper by using wavelet transformation, we proposed an approach based on the difference between the slope of internal fault current of Trans and invasion current of capacitor bank switching which is able to distinguish the cycle of internal fault current from invasion current of capacitor bank switching. Conclusively, simulated information revealed that the proposed algorithm is a precise algorithm to provide differential protecting. Moreover, in all cases, the time of fault occurrence was distinguished in less than quarter of time which shows it's high rate. These days due to the over development and emerging of new technologies and sensitive tools, and also introducing new discussions of Privatization, necessity of more precise surveying of this transient is unavoidable. In this paper, the problem issued from capacitor bank switching was studied from the view of protecting tools and power quality problems and some new and quick approaches were proposed to a conquest of problems using wavelet transformation.
Given the problems caused by new requirements electrical energy is good quality, less research has been done that could be a new topic for further research. In this paper, the problems caused by the launch of the induction motor overcurrent relay examined. The effect of the following on the relays could be the subject of further research.

- Notime switching lines

- Capacitor switching, both as single and back-to-back

- Capacitor switching, both as single and back-to-back.

Acknowledgements:

Authors express their gratitude to all such staff and academicians who directly/indirectly helped us.

\section{References:}

Abu-Elanien, A.E.B.; Salama, M.M.A.; (2009 ): A Wavelet-ANN Technique for Locating Switched Capacitors in Distribution Systems. IEEE Trans. PowerDel., (24)2: 400409.

Boris, B. \& Peter, P. (2006): Classification of Power Disturbances using Fuzzy Logic", Proc. of IEEE Power Electronics and Motion Control Conference, EPE-PEMC, 2006.

Guzman, A., Zocholl, S., Benmouryal, G. \& Altuve, H.J. (2001): A current based solution for transformer differential protection-Part I: Problem statement, IEEE Trans. Power Del., (16) 4:485-491.

IEEE (1992): Guide for Application of Shunt Power Capacitors, IEEE Std. 1036-1992, New York.

Kanitpanyacharoean, W. \& Premrudeepreechacharn, S. (2004): Power quality problem classification using wavelet transformation and artificial neural networks. In Proc. of Power System Conf. and Exposition, pages: 1496-1501.

Karthik, N., Gafoor, S.A. \& Kalavathi, M.S. (2011): Classification of Power quality problems by wavelet Fuzzy expert system. IEEE Trans. Power Del., (1)3.

Kim, J., Grady, W.M., Arapostathis, A., Soward, J.C. \& Bhatt, S.C. (2002): A time-domain procedure for locating switched capacitors in power distribution systems. IEEE Trans. Power Del., (17) 4:1044-1049.

Mohammadi, S., Soleymani, S. \& Mozafari, B. (2013a): A stochastic programming approach for optimal microgrid economic operation under uncertainty using $2 \mathrm{~m}+1$ point estimate method. L.Ren. Sust. Energy, 5:033-112

Mohammadi, S., Soleymani, S. Mozafari, B. \& Niknam, T. (2013b): An Adaptive Modif ied Firefly Optimisation Algorithm based on Hong's Point Estimat Method to optimal Method operation management in a microgrid with consideration of uncertainties. Energy, 51:339-348.

Mohammadi, S., Soleymani, S. \& Mozafari, B. (2014): Scenariobased stochastic operation management of Micro Grid including Wind, photovoltaic, Micro-Turbin, Fuel Cell and Energy Storage Devices. Int.J. Elec. Power., 54:525-535.

Parsons, A. C., Grady, W.M., Powers, E. J. \& Soward, J. C. (200o): A direction finder for disturbances based upon disturbance power and energy. IEEE Trans. Power Del., 15(3): 1081-1086.

Wang, M.H, Tseng, Y-F. (2011): A novel analytic method of power quality using extension genetic algorithm and wavelet transform. Expert Sys. Appl., 38:12491-12496 